\title{
Analysis the characteristics of traditional Chinese medicine in English literature development in modern history
}

\author{
Mingming $\mathrm{Fu}^{1}$, Xiangdong Meng ${ }^{2}$, Zhiping $\mathrm{Li}^{3}$ \\ ${ }^{1}$ Foreign Language Department, North Sichuan Medical College, Nanchong, China; ${ }^{2}$ Nanchong Central Hospital, The Second Clinical Medical \\ College, North Sichuan Medical College (University), Nanchong, China; ${ }^{3}$ Teaching and Research Section of Medical History, Harbin Medical \\ University, Harbin, China \\ Contributions: (I) Conception and design: M Fu; (II) Administrative support: Z Li; (III) Provision of study materials or patients: X Meng; (IV) \\ Collection and assembly of data: M Fu; (V) Data analysis and interpretation: X Meng; (VI) Manuscript writing: All authors; (VII) Final approval of \\ manuscript: All authors. \\ Correspondence to: Xiangdong Meng. Nanchong Central Hospital, The Second Clinical Medical College, North Sichuan Medical College (University), \\ Nanchong 637000, China. Email: Mlmb2021@126.com; Zhiping Li. Teaching and Research Department of Medical History, Harbin Medical \\ University, 150 Haping Road, Harbin 150000, China. Email: Jxdx112@163.com.
}

\begin{abstract}
The large-scale exchange and spread of traditional Chinese medicine (TCM) in the West began in the 17th century. From the first English Chinese medicine book "gout collection" published in London in 1676, the British began to understand the mysterious and ancient oriental medicine of TCM. Britain is one of the earliest countries where TCM began to spread. TCM is an important carrier of China's excellent traditional culture. With the development of the world's medical technology and the continuous improvement of China's cultural soft power, the cross-cultural communication of TCM has become a characteristic business card for China to go to the world. For the research of a work, we must start from the source, so it is very important to first count the history of TCM external communication, and then systematically analyze and study the various phenomena in this history, so as to summarize the experience and inadequacy of TCM external communication process, and provide feasible guidance for future TCM research, And promote the effective development of TCM, and ultimately spread TCM culture to the international community more comprehensively and accurately. Although the greater than 300 hundred years' history of traditional Chinese medicine (TCM) spreading throughout Britain has been continuously mentioned in literature, studies on the historical development of TCM in Britain are rare. In this paper, the authors gathered information including the chronological statistics and stages of the 300 hundred years' dissemination of TCM in Britain, in order to provide more historical data and research materials for the spread of Chinese medicine in Britain.
\end{abstract}

Keywords: Traditional Chinese medicine (TCM); England; communication; research

Submitted Jun 16, 2021. Accepted for publication Jul 26, 2021.

doi: 10.21037/apm-21-1820

View this article at: https://dx.doi.org/10.21037/apm-21-1820

The great geographical discoveries of the 15 th century opened up a new world of economic and cultural exchange between the East and West. When westerners arrived in China, they not only introduced western medicine to China, but also conveyed traditional Chinese medicine (TCM) back to the West, via the translation and dissemination of a variety of TCM classic works such as the such as the
Compendium of Materia Medica, Shennong's Classic of Material Medical, Treatise on Cold Pathogenic and Miscellaneous Diseases, Treatise on Cold Pathogenic Diseases, Correction on Errors in Medical Classics and so on. Through the study of modern scientific thinking by western medical practitioners and international sinologists, TCM has been introduced to western countries in different stages of influx over various 


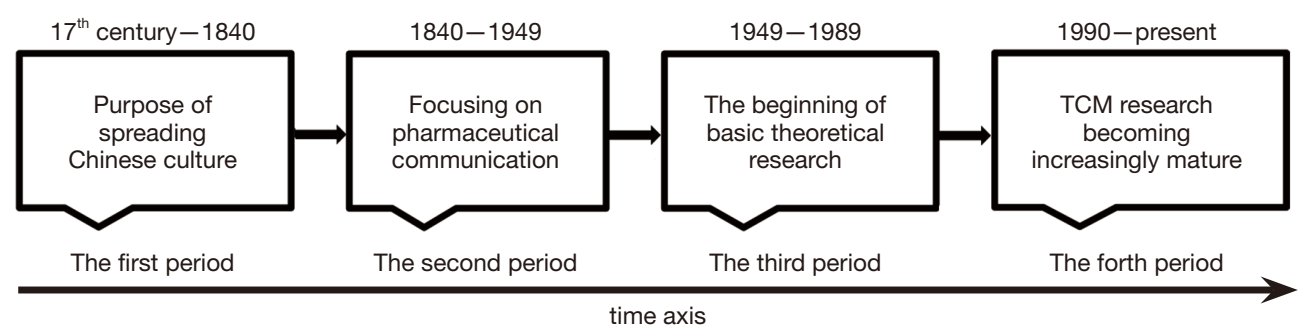

Figure 1 Development timeline of traditional Chinese medicine in UK.

historical chapters. The UK is one such western country with a long history of interest in TCM. The unique charm of TCM has facilitated it being welcomed into Britain.

The study of TCM in England can be roughly divided into the following 4 periods (See Figure 1 for details), each of which holds its characteristics against the background of the times.

\section{TCM research for the purpose of spreading Chinese culture (17th century to 1840)}

\section{English translation of TCM literature from the $17 \mathrm{th}$ century to 1840}

During the Renaissance period in Europe in the 17th century, England, as the cultural center of the Renaissance, was highly emancipated and willing to accept and study foreign medicine. During this period, TCM was introduced to England due to its unique curative effects. According to current records, the earliest treatise on TCM to appear in England was the Treatise of the Gout ("On Gout") published in London in 1676, by Busschof (1). It was also the earliest monograph on TCM in the English language in Europe. The book introduces the magical effects of moxibustion in TCM through the author's recounting of personal experience, which was recognized by Europeans at the time. The book translates moxibustion into "moxa", which is a transliteration of "mogusa/も ぐさ” in Japanese. Originally published in Amsterdam in 1675, and then in London a year later, the book gained widespread attention due to the prominent social status of its author (2). As the center of TCM transmission at the time, London published over 10 English language monographs on TCM (see Table 1 for details).

\section{Analysis of the characteristics of TCM literature translated into English from the 17th century to 1840}

During this stage, the English translations of TCM literature published in the UK were translated by foreign authors, most of whom were British. Such translators were "driven by interest" and the content of the English-translated literature did not involve TCM pharmacology. Most of these authors had no knowledge of TCM theory. Predominantly, the notes and comments in the literature were based on "culturally loaded" sentiments. The famous sinologist of modern times and founder of the French sinology research system, Rémusat, once made a critical comment: "How accurate is the knowledge of traditional Chinese medicine translated or introduced to the west by missionaries or doctors? If the translator is not proficient in Chinese, does not understand traditional Chinese medicine, or even has not received Western medicine education, it is impossible to read the traditional Chinese medicine or the classics of traditional Chinese medicine." (3). Therefore, the English-translated literature of this stage played a key role in popularizing western countries in the ancient eastern countries, and the awareness that the English-translated literature served a great role in spreading the awareness of TCM in the west at the time.

\section{TCM research focusing on pharmaceutical communication (1840 to 1949)}

\section{English translation of British TCM literature from 1840 to 1949}

In the middle of the 19th century, western laboratory research prevailed, and pharmacology became a specialized subject. Since ancient times, the western world has long been concerned by the magical curative effects of TCM, and the study of TCM became the focus of the spread of TCM in Britain during this period. The British bachelor of "Pharmaceutics" and "Pharmaceutical Chemistry" (Read BE, 1887-1949) translated and disseminated the contents of the Compendium of Materia Medica: translated separately as The Pen Ts'ao Minerals and Stones; Chinese Materia Medica, Animal Drugs; Chinese Materia Medica, Dragon, and Snake 
Table 1 Statistics of English monographs on TCM published in England from the $17^{\text {th }}$ century to 1840

\begin{tabular}{|c|c|c|c|c|}
\hline Year & Translator & Chinese title & English title & Published \\
\hline 1683 & Rhyne G.T. & Lun Guan Jie Yan & Unknown & London \\
\hline 1707 & Floyer John & Yi Sheng Zhen Mai De Biao & The Physician's Pulse-Watch & London \\
\hline 1736 & Brookes R. & Zhong Guo Tong Shi (reprinted in 1739 and 1741) & The General History of China & London \\
\hline 1821 & Churchill J.M. & Zhen Shu Quan Shu & A Treatise on Acupuncturation & London \\
\hline 1822 & Larrey D.J. Dunglison & Jiu Shu Zai Zhi Liao Zhong De Ying Yong & $\begin{array}{l}\text { On the Use of the Moxa as a } \\
\text { Therapeutical Agent }\end{array}$ & London \\
\hline 1825 & Boyle J. & Jiu Shu Zhuan Lun & A Treatise on Moxa & London \\
\hline
\end{tabular}

TCM, traditional Chinese medicine.

Drugs; Chinese Materia Medica, Turtle, and Shellfish Drugs; Chinese Materia Medica, Insect Drugs; and Famine foods listed in the Chiu Huang Pen Ts'ao (4).

In the English translation of Compendium of Materia Medica, ReadBE [1887-1949] said, "There are 4 kinds of Compendiums: Dragon, Snake, Turtle, and Shellfish to those four kinds of animals there are Birds in Yusuo's Compendium of Materia Medica, which is more in line with the modern medicine." (5). In order to meet the needs of modern medicine, the English translation of TCM materials has lost a lot of the original flavor of TCM. The English translation of Compendium of Materia Medica may also look more like a modern botanical and nutritional research text written from a western perspective. There are few translations of the four $q i$, five flavors, harvesting, efficacy, indications, processing, and compound prescriptions of TCM, ignoring the already established research results of TCM itself.

We show the results of the periodical research on English translations of TCM in Britain during this period in Table 2.

\section{Analysis of characteristics of English translations of TCM literature from 1840 to 1949}

At this stage, the authors of English translations of TCM were mainly westerners. Western medicine developed rapidly at the beginning of the 20th century, and was recognized by the international community. In the era of "Western Learning" spreading to the east, the aggressive infiltration of western medicine greatly affected the spread of TCM to the west. Westerners often impose many western medical opinions and medical theories When Westerners translate Chinese medicine literature into English, they often inject a lot of Western medical views and theories, and often neglect the theory, method, prescription and medicine system of TCM. Therefore, the literature of this period still failed to authentically showcase Chinese medicine to Western countries, and the purpose of accurately disseminating TCM had not yet been achieved.

\section{The beginning of basic theoretical research in TCM (1949 to 1989)}

\section{English translation of TCM literature from 1949 to 1989}

At the beginning of the founding of the People's Republic of China, there were fewer exchanges between China and the United Kingdom, and TCM exchanges were mostly conducted through unofficial channels, such as TCM social groups and academic activities in British civil society. The predominant representative body was the British Acupuncture Association Register (BAAR) founded by Felix Mann in the United Kingdom in 1961. It was the earliest acupuncture organization in the United Kingdom. The society published a journal entitled Brit 7 Acupuncture in 
Table 2 Statistics on TCM English monographs published in England from 1840 to 1949

\begin{tabular}{|c|c|c|c|c|}
\hline Year & Translator & Chinese title & English title & Published \\
\hline 1862 & Hanbury D. & Zhong Guo Yao Wu Zhu Jie & Notes on Chinese Materia Medica & London \\
\hline 1863 & Gordon C.A. & $\begin{array}{l}\text { Cong Yi Xue Guan Dian Kan Zhong Guo, } \\
\text { 1860-1861 }\end{array}$ & $\begin{array}{l}\text { China from a medical point of view in } 1860 \\
\text { and } 1861\end{array}$ & London \\
\hline 1898 & Bretschneider E.V. & Ou Zhou Ren Fa Xian Zhong Guo Zhi Wu Shi & $\begin{array}{l}\text { History of European Botanical Discoveries in } \\
\text { China }\end{array}$ & London \\
\hline 1929 & Hooper D. & $\begin{array}{l}\text { Zhong Guo Yao Wu: Zai Ma Lai Xi Ya Zhong } \\
\text { Yao Dian Li De Yao Cai }\end{array}$ & $\begin{array}{l}\text { On Chinese Medicine: Drugs of Chinese } \\
\text { Pharmacies }\end{array}$ & London \\
\hline 1945 & Cox E.H.M. & $\begin{array}{l}\text { Zhong Guo Ji Xi Zang Bian Jing Zhi Wu Cai } \\
\text { Fang Shi }\end{array}$ & $\begin{array}{l}\text { Plant Hunting in China: A History of Botanical } \\
\text { Exploration in China and the Tibetan Marches }\end{array}$ & London \\
\hline
\end{tabular}

TCM, traditional Chinese medicine.

1964 (6). The journal publishes 4 times a year, and it has columns on clinical, philosophy, research progress, new methods of acupuncture, recent newsletters or minutes, reports, and so on. It also contains world acupuncture reviews, arguments, and news.

During this period, the great work of Doctor J. Needham emerged. The author of the famous British Scientist column and a member of the Royal Society of Medicine, Dr. Needham studied the History of Science and Technology, and the History of Science and Civilization in China (7). This led to increased worldwide attention for TCM.

After U.S. President Nixon's visit to China in 1972, the prelude to the spread of Chinese medicine worldwide began. The communication between China and the UK was increasing, and the channels for the spread of TCM were gradually diversifying. The study of TCM in the UK was no longer limited to acupuncture and herbal medicine and research on the basic theories of TCM had truly commenced (Table 3).

\section{An analysis of the characteristics of TCM literature translated into English from 1949 to 1989}

At this stage, authors of TCM English translations began to gain awareness of the traditional Chinese culture behind TCM. For example, in the sixth volume of Chinese History of Science and Technology, Dr. Joseph Needham first introduced "medicine in Chinese culture" (7). With the increasingly frequent exchanges between China and the international community, a larger volume TCM documents were translated by both Chinese citizens and westerners. Mr. Zheng Jinsheng from the Research Institute of Chinese Medical History and Chinese Academy of TCM, participated in the compilation of many English works of TCM by Mr. Paul U. Unschuld. Paul U. Unschuld said "Believe in their [Chinese scholars] work", and set about directly transmitting legitimate TCM knowledge. First, they provided accurate information for other scholars who do not understand Chinese, so that they might carry out comparative research. Secondly, they presented the broad array of materials for those who were interested in applying Chinese medicine to clinical experiments, so that they could make a fair comparison between eastern and western medical traditions (8). On the one hand, Chinese researchers can provide detailed materials and bases for the study of the theoretical system of TCM and Chinese traditional culture. On the other hand, language and crosscultural barriers have been discussed and exchanged by 
Table 3 Statistics on English monographs on TCM published in the UK from 1949 to 1989

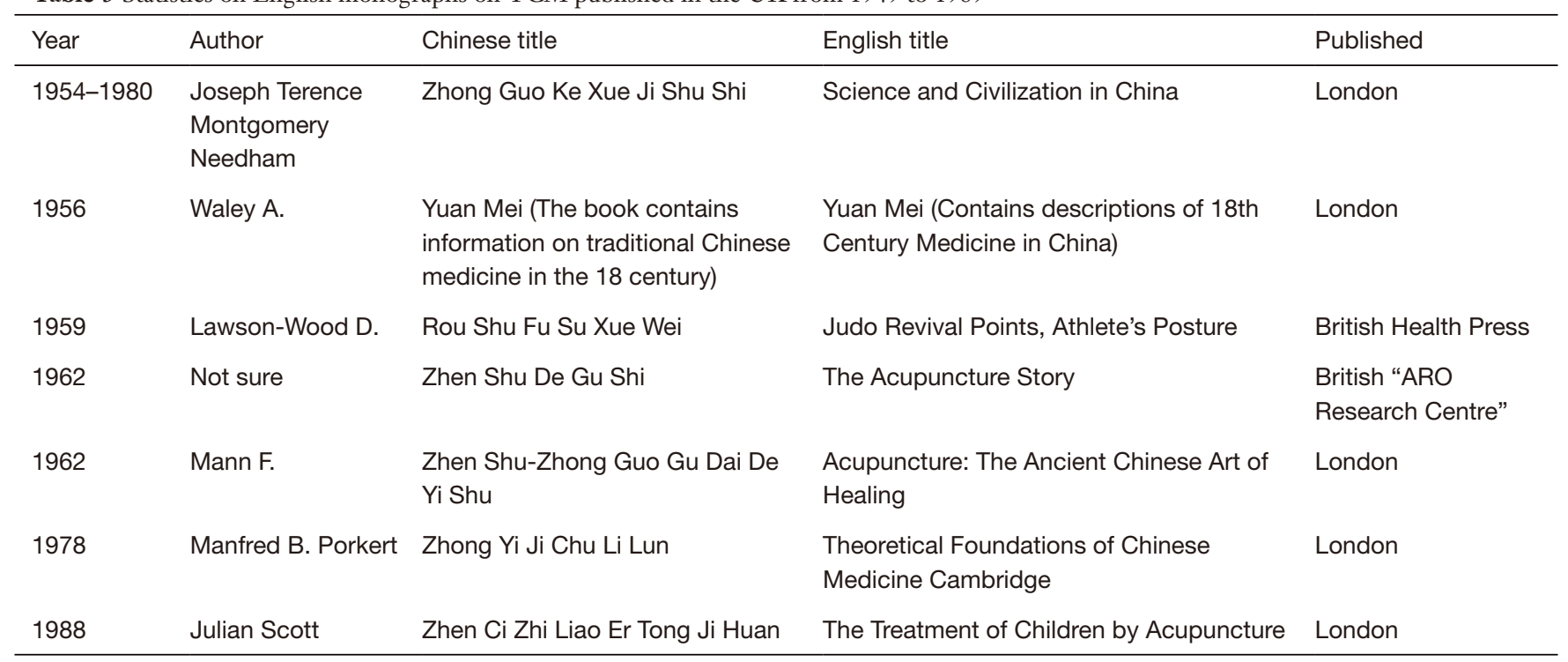

TCM, traditional Chinese medicine.

both sides, and it is possible to tweak the suitability of such materials to increase western acceptance, retaining cultural connotation wherever possible, and spread the medical efficacy of TCM to the maximum extent. Therefore, the English-translated documents from this period have been more widely spread in Britain, among all western countries, and opened up a new realm of knowledge and a new situation of Sino-foreign cooperation.

\section{The research of TCM is becoming increasingly mature (1990-present)}

\section{English translation of Chinese medicine literature from 1990-present}

According to Professor Ma Boying, after the 1990s, many Chinese doctors landed jobs in the UK, and many British citizens began to learn TCM. According to the Royal Botanical Gardens (RBG), by 1998, there were 3,000 TCM clinics in the UK (9). The number is the sum of the other countries of Europe combined. TCM has become the main source of income for British Chinese, second only to catering, and the UK has also become the second largest Chinese patent medicine market outside Asia. It can be seen that TCM, especially herbal, has a certain degree of recognition among the British people. In 1993, the first Chinese medicine clinic in a UK national hospital was listed for consultation. Outpatient pharmacies provided a growing variety of commonly used Chinese herbs and proprietary Chinese medicines. Some public hospitals, such as the London St. Thomas Hospital and Oxford Hospital, have invited famous Chinese doctors, such as Zhu Liangchun and $\mathrm{Wu}$ Boping, to visit them. Some Chinese doctors have been awarded the title of Visiting Professor.

In the UK, in order to meet the needs of TCM learners, the research on TCM further focuses on the arrangement of basic medicine. Giovanni Maciocia, a British TCM practitioner and author, wrote the Practice of Chinese Medicine in 1994, and then completed the Practice of Chinese Medicine in 1998 (10). In 2004, Bensky, Clavey, Stoger, Gamble wrote Chinese Herbal Medicine: Materia Medica (Third Ed.). William Maclean and Jane Lyttleton wrote Clinical Handbook of Internal Medicine: The Treatment of Disease with Traditional Chinese Medicine. The most representative TCM text of this time is the Fundamentals of Chinese Medicine written by Wiseman, which was republished in 1995. Paul Unschuld spoke highly of the book "this book will make bistory, and the standards it sets cannot be ignored by anyone who wants to write about TCM in the future (11)".

It is worth mentioning that the most important EnglishChinese dictionary of TCM was compiled in 1995 by the British author Nigel Wiseman.

Unschuld pointed out "Nigel Wiseman's EnglishChinese Chinese-English dictionary of Chinese medicine has an unprecedented list of about 10,000 TCM words, 2,000 prescription names, 1,700 TCM names, and 1,500 acupuncture points in 
innovative and groundbreaking translations," (12). Wiseman's vocabulary "is not only adopted by many translators, but also designated by Paradigm Publications and Blue Poppy Press, two of the three major Chinese medicine literature publishers in the US, as the English vocabulary standard for its publishing quality." (13).

As the disease spectrum has evolved, the control of chronic diseases has become a focus of social concern. In light of the reality of China's medical and health care situation, the Chinese government has decided to vigorously develop TCM and strengthen the research of TCM. It has accomplished universally recognized achievements in the development and application of traditional medicine to promote health and treatment of diseases, and acupuncture therapy, as the representative modality of TCM, has been widely embraced internationally (14). From this perspective, foreign journals have tended to focus on alternative medicine, especially acupuncture and herbal medicine. Even in 2004, Oxford University Press had established a special issue Evidencebased Complementary and Alternative Medicine (15), which further standardized the English translation terms of TCM and provided necessary conditions for the better and faster dissemination of TCM.

The advent of the age of information technology has been a boon for the dissemination of TCM. The sharing of information resources has enabled faster communication between China and foreign countries, and TCM research in Britain has become more specialized. For example, we can now easily locate numerous TCM research results on the website www.elsevier.com in the UK, or the publication websites of various universities, such as Cardiff University library (online articles).

\section{An analysis of the characteristics of TCM literature in English translation from 1990 to present}

Since the 1990s, TCM has made great progress in the UK, various TCM diagnosis and treatment institutions and TCM schools have continuously emerged, and most of them have created their own special journals, which provide a platform for the dissemination of TCM, so that relevant TCM information can be displayed in a timely manner for uptake by the Chinese medicine community. Journals and magazines have become the main avenues of TCM communication and development in Britain. Most gratifyingly, various reference books for TCM learners keep appearing and becoming more standardized. With the exception of some local TCM research institutions that regularly or irregularly publish TCM academic journals, some technical reports or standardized proposals of the World Health Organization (WHO) are also published in the UK and sold on to various other countries. For example, the Proposed Standard International Acupuncture Nomenclature, written by the WHO, contains Chinese pinyin and English abbreviations of full acupuncture meridian names (16).

\section{Discussion}

\section{TCM is mainly used in rehabilitation and health care in $U K$}

In clinical practice, TCM is regarded as "alternative medicine" in the United Kingdom. Western medicine is used to treat diseases that have already occurred. With the improvement of people's living standards and subhealth caused by various pressures, western medicine has also begun to pay attention to the field of health care and rehabilitation of TCM "The British health care system itself has the practice of using herbal medicine to suppress the cold virus." Liangwei Zhu, a member of the Royal Society of medicine and the University of Cambridge hospital in England, said that under the current COVID-19 epidemic, the British national health system has adopted a combination of Chinese and Western medicine in various preventive and therapeutic measures. For example, British health doctors often advise patients to use lemon and Lycium barbarum to improve their immunity. At present, there are mainly set up TCM clinics in the UK, However, with the implementation of the "one belt and one way" strategic development plan [2016-2020], Chinese medicine will create a new pattern of all-round opening up. This plan will effectively promote the development of TCM in all directions in European countries. However, how to accurately analyze and grasp the European market demand, break through the bottleneck of Chinese medicine policy and trade, and promote the healthy and stable development of Chinese medicine internationalization is the focus of the industry.

\section{TCM has a long history in Britain}

TCM appeared earlier in Europe. From 1860 to 1862, Daniel Hanbury, academician of the Royal Society of England, published the monographic study of Notes of Chinese Materia Medica in the Fournal of Pharmacy by stages over the past 100 years, missionaries, doctors and scholars from France, Germany, Britain, Russia and other countries have been waiting for China to make field visits and collect samples of TCM, then go back to Europe for research. 
Many monographs on research and introduction of TCM have emerged, such as Angelica sinensis, ginseng and other herbal materials have also been made into medicine and put into the market. Although western medicine did not use the TCM's principle, method and prescription herbal system to match with TCM, but was keen on the TCM extract to treat diseases, it still accepted the use of TCM earlier, and the literature of TCM was constantly translated or written. However, due to the differences in language and writing, and the existence of cultural deficiency, TCM did not get the maximum spread in the UK, At present, TCM is mostly used for health care. Only by combing the historical English translation of TCM literature, can we understand the characteristics and trends of TCM communication process, so as to provide the basis for better communication of TCM in the UK and even the world in the future.

\section{Complementary advantages of TCM and Western medicine for the benefit of mankind}

In fact, both TCM and Western medicine have their own mature medical system, and have made brilliant achievements in the long history of development. From 220 AD, Hua Tuo invented the anesthetic drug used in surgery, named Ma boiling powder, to treated current COVID-19 epidemic with TCM, these all embodied their advanced nature and special superiority. Laboratory medicine of Western medicine has also made certain achievements. Both sides play an irreplaceable role and can complement each other to better promote the development of world health care. Zilat, chairman of the Nobel Committee for physiology or medicine, told Xinhua that "Chinese female scientist Youyou Tu isolated artemisinin from traditional Chinese medicine and applied it to malaria treatment, which shows that traditional Chinese berbal medicine can also bring new inspiration" She believed after the purification of modern technology and the combination with modern medicine, the achievements of Chinese herbal medicine in the treatment of diseases were remarkable. It can be seen that both TCM and Western medicine are medical systems serving human society. It is unnecessary to emphasize which kind of medicine is more advanced or advantageous, and which kind of medicine has greater and far-reaching influence. The essence of medical research is to benefit more talents through research.

\section{Conclusions}

Britain, as one of the countries with the most substantial history of the development and dissemination of TCM in the western world, was selected by us to perform a systematic analysis and research of the history of the development of translation of TCM documents. We have summarized the characteristics and rules of TCM communication, which can provide a feasible reference for the future external communication of TCM, and provide more historical evidence for improved communication of TCM to the international community with the backdrop of "One Belt One Road" (OBOR), also known as the Belt and Road Initiative (BRI).

\section{Acknowledgments}

Funding: This study was funded by 2016 Heilongjiang Province Postdoctoral Funding Project (LBH-Z16252) "Development of traditional Chinese medicine in Britain", 2021, the "14th five year plan" of Nanchong Federation of Social Sciences (NC21A016).

\section{Footnote}

Conflicts of Interest: All authors have completed the ICMJE uniform disclosure form (available at https://dx.doi. org/10.21037/apm-21-1820). The authors have no conflicts of interest to declare.

Ethical Statement: The authors are accountable for all aspects of the work in ensuring that questions related to the accuracy or integrity of any part of the work are appropriately investigated and resolved.

Open Access Statement: This is an Open Access article distributed in accordance with the Creative Commons Attribution-NonCommercial-NoDerivs 4.0 International License (CC BY-NC-ND 4.0), which permits the noncommercial replication and distribution of the article with the strict proviso that no changes or edits are made and the original work is properly cited (including links to both the formal publication through the relevant DOI and the license). See: https://creativecommons.org/licenses/by-nc-nd/4.0/.

\section{References}

1. 1. Busschof H. Of the gout. London: Printed by H. C. and sold by Moses Pitts, 1676.

2. William T. An Essay Upon the Cure of the Gout by Moxa, Written to Monsieur De Zulichem in Miscellanea. 
London: Jacob Tonson, 1693:212.

3. Gao X. The spread and study of traditional Chinese medicine in the west since the 15 th century. Chin Med Cult 2015;6:23.

4. Wang J, Fu W. Bibliography of foreign medical literature in China. Museum of Medical History, Shanghai College of Traditional Chinese Medicine 1963;54-57.

5. Yi B. Chinese medicine has been a scientific experimenter for nearly a decade. Chin Med J 1937;98.

6. Zuo Y. Overview of traditional Chinese medicine abroad. Beijing: People's Health Publisher, 1998:287.

7. Joseph N. The sixth volume of Chinese History of Science and Technology, Sixth fascicle: Medicine. Beijing: Science Press, 2013:3.

8. Unschuld PU. Western Research on Chinese medical history: achievements, methods and Prospects. Ricardo Mak King Sang translate. Contemp China Hist 2003;2:1-14.

9. Ye X. Traditional Chinese medicine in the UK in the past forty years: an interview with Professor Bo-ying Ma. J Integr Med 2016;14:77-83.

10. Lyttleton MW. Clinical Handbook of Internal Medicine: The Treatment of Disease with Traditional Chinese Medicine. Volume 1 (2nd Edition). Sydney: University of
Western Sydney, 2000:XI.

11. Wiseman N, Elisa A. Fundamentals of Chinese Medicine: Revised Edition. Brookline MA: Paradigm Publications, 1995:45.

12. Unschuld PU. Foreword by Paul Unschuld. EnglishChinese Chinese-English Dictionary of Chinese Medicine. Changsha: Hunan Science and Technology Press, 1995:1.

13. Wiseman N, Ye F. A Practical dictionary of Chinese Medicine. Beijing: People's Medical Publishing House, 2003:3.

14. Zhang D, Cheng Z, Peng R. Medicine in the 20th century: reviewing and thinking about medicine and philosophy. Med Philos 2001;22:61.

15. World Health Organization. WHO International Standard Terminologies on Traditional Medicine in the Western Pacific Region. Available online: https://apps.who.int/iris/ handle/10665/206952 (2007:16).

16. Liu J, Hou Z. Chinese Medicine in the world -- 60 years since the founding of the People's Republic of China, TCM has been on the road to the world. Beijing: Beijing Science and Technology Press, 2009:167.

(English Language Editor: J. Jones)
Cite this article as: Fu M, Meng X, Li Z. Analysis the characteristics of traditional Chinese medicine in English literature development in modern history. Ann Palliat Med 2021;10(8):9251-9258. doi: 10.21037/apm-21-1820 